\title{
Penetrating neck injury from a screwdriver: can the No Zone approach be applied to Zone I injuries?
}

\author{
Nikita R Bhatt, ${ }^{1,2}$ Morgan McMonagle ${ }^{1}$
}

${ }^{1}$ Department of Surgery, University Hospital Waterford, Waterford, Ireland ${ }^{2}$ Department of Surgery, University Hospital Limerick, Limerick, Ireland

\section{Correspondence to}

Dr Nikita R Bhatt,

nikitarb89@gmail.com

Accepted 16 November 2015

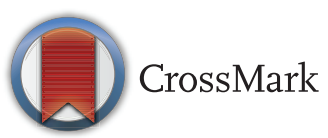

To cite: Bhatt NR, McMonagle M. BMJ Case Rep Published online: [please include Day Month Year] doi:10.1136/bcr-2015212666

\section{SUMMARY}

The newer approach to management of penetrating neck injuries (PNI) involves the No Zone approach: comprehensive physical examination combined with CT angiography for triage to effectively identify or exclude vascular and aerodigestive injury. This approach, however, has a low negative exploration rate; there is risk of missing occult injuries especially Zone I and III PNI. We report a case of a patient with PNI to Zone I of the neck who was haemodynamically stable at presentation; CT scan revealed complete occlusion of the common carotid artery. Immediate surgical exploration revealed an occult hypopharyngeal injury in addition to the arterial trauma, which was missed on the CT scan. Hence the No Zone approach needs cautious clinical application, especially in Zone I injuries.

\section{BACKGROUND}

Penetrating neck injuries (PNI) often involve multiple concomitant structures, which makes surgical exposure and management challenging. ${ }^{1}$ PNI are divided into three anatomical zones (figure 1), which helps in the approach and management of wounds. ${ }^{2}$ Zone I injuries are common in stabbing wounds and almost one-third are asymptomatic at presentation. ${ }^{3}$ Multidetector CT angiography (CTA) has a high sensitivity and specificity of almost $90-100 \%$ and $93.5-100 \%$, respectively, for PNI. ${ }^{4}$ Hence, according to the new No Zone approach for managing PNI, comprehensive physical examination combined with CTA is adequate for triage to effectively identify or exclude vascular and aerodigestive injury. ${ }^{5}$ This approach, however, may not be adequate to diagnose all injuries in a Zone I trauma.

\section{CASE PRESENTATION}

A 46-year-old man, a mechanic, presented to our emergency department after an assault where he sustained a PNI from a screwdriver. On admission, he was haemodynamically well with no abnormal neurological findings and no obvious signs of airway compromise or oesophageal injury such as dysphagia/odynophagia. On examination, there was a wound present in the right posterior triangle of the neck (Zone I) (figure 2).

\section{INVESTIGATIONS}

CT scan revealed a large haematoma deep within the right side of the neck, with tracheal deviation and radiological evidence/mild tracheal compression (figure 3). In addition, there was complete occlusion of the right common carotid artery
(CCA) (figure 4), with surrounding haematoma, consistent with penetrating vessel injury with acute thrombotic occlusion. There was no radiological evidence of cerebral embolisation or intracranial vessel occlusion.

\section{TREATMENT}

It was decided to perform emergency surgical management of the wound. Emergency airway management for the deviated, compressed trachea in the form of rapid sequence intubation was performed in the operating theatre. Following uneventful airway management, a standard carotid dissection was performed anterior to the sternocleidomastoid muscle and internal jugular vein. The CCA, external carotid artery and internal carotid artery (ICA) were dissected and controlled. The surrounding haematoma at the CCA was maintained until definitive vascular control was obtained, and proximal control from within the chest was unnecessary.

Intraoperative findings were: through-andthrough puncture laceration of the CCA with a small concomitant hypopharyngeal perforation $(1.5 \mathrm{~cm})$. After systemic heparinisation and clamping of the CCA, a longitudinal arteriotomy was performed to inspect the vessel interior, revealing a large thrombus in situ with intimal injury (figure 5). The thrombus was evacuated and the intima dissected back to the healthy adherent tissue. The posterior wall of the vessel was noted to be lacerated down to thin adventitia and deemed too damaged for safe repair. A Javid shunt was inserted while the long saphenous vein (LSV) was harvested for successful interposition (non-reversed) grafting of the injured CCA using $5 / 0$ prolene. The laceration in the hypopharynx, repaired with interrupted 3/0 absorbable polydioxanone sutures and a viable flap of sternocleidomastoid muscle, was mobilised as a muscle flap over the hollow viscus repair to protect the vascular repair from potential contamination and the potential for graft 'blow-out'. The operative site was irrigated and drained ( $1 / 4$ in redivac drain), and the wound was closed.

\section{OUTCOME AND FOLLOW-UP}

The patient went on to make an uneventful recovery and was safely discharged from hospital on day 7 postoperative. His assailant received a 9-year sentence for attempted murder.

\section{DISCUSSION}

Zone I and III injuries each form approximately $25 \%$ of the PNI, and are challenging both in terms of evaluation and surgical management. ${ }^{6}{ }^{7}$ In $16 \%$ 


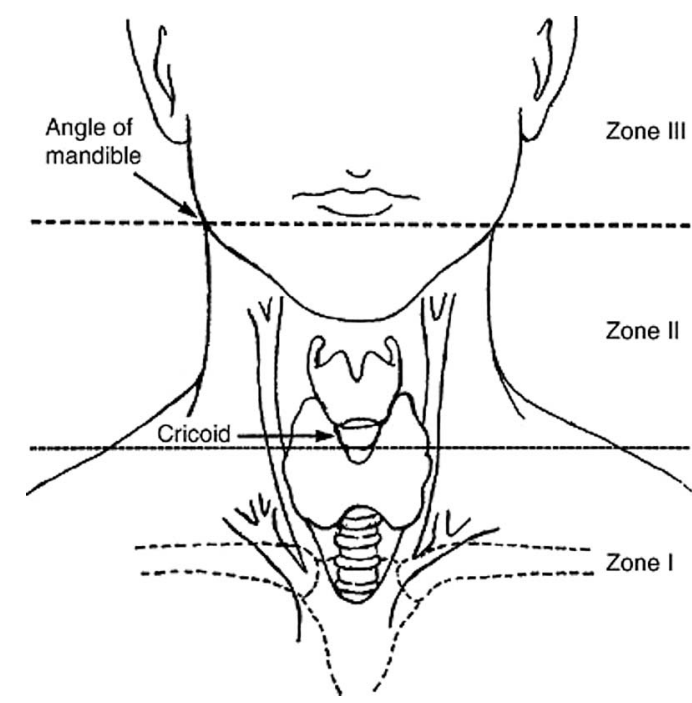

Figure 1 Zones of neck.

of the cases, more than one zone is involved. ${ }^{8}$ Higher mortality rates are reported in Zone I injury on account of the challenges involved in exposure and proximal vascular control in this zone. ${ }^{9}{ }^{10}$ Death after neck trauma is usually caused by airway obstruction, exsanguination, cervical spine injuries, cerebral ischaemia due to carotid and, occasionally, by vertebral artery injuries or sepsis.

Management of PNI is dictated by physiology, especially the haemodynamics of the patient and potential injuries. Haemodynamically unwell patients or those with hard signs of vascular injury should undergo immediate surgical management. Patients with soft signs of vascular injury or just a suspicion of vascular injury do not warrant immediate surgery (in the absence of other indications for surgical exploration) and may be safely observed or investigated. ${ }^{10}$

PNI management, traditionally, was based on the zone of injury, which, though providing a useful guideline, has certain disadvantages, such as making it difficult to determine zones in multiple injuries, and offering poor correlation between surface location and internal organ involvement. This selective zonebased approach was created by mandatory exploration in stable asymptomatic Zone II PNI with imaging studies in stable Zone I and III injuries. In addition to routine imaging studies, liberal use of angiography and routine oesophageal evaluation in the

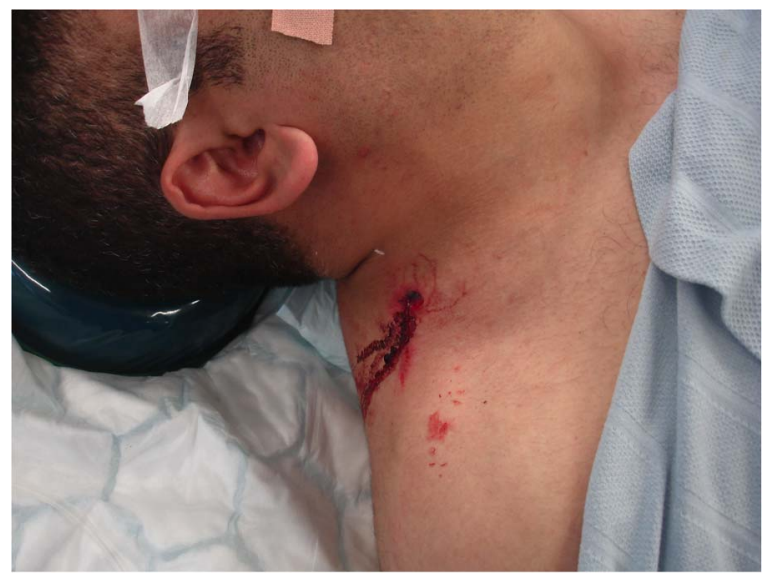

Figure 2 Site of penetrating neck injuries in Zone I.

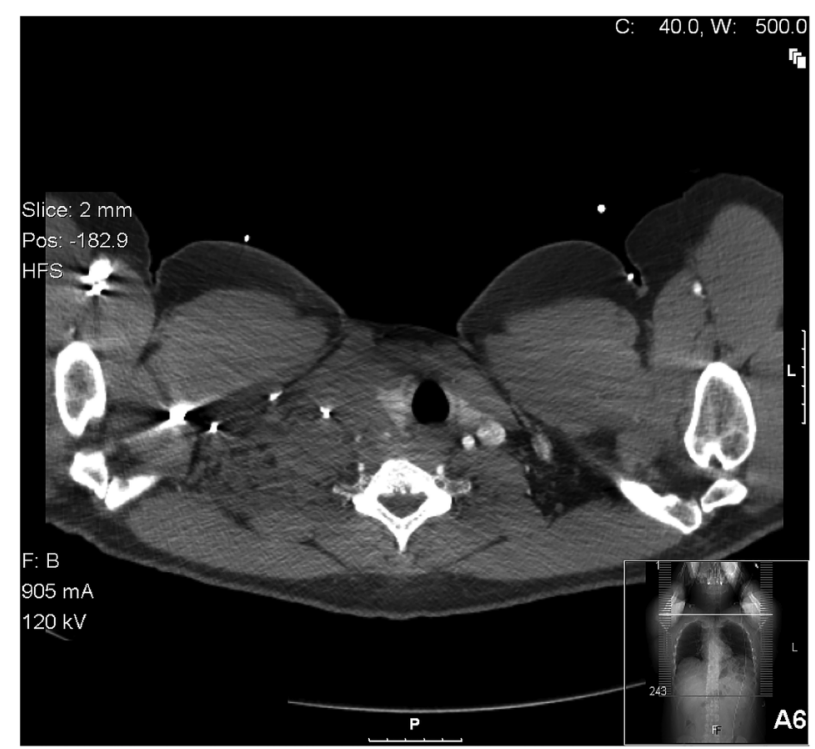

Figure 3 Axial section of CT scan with right common carotid artery haematoma.

form of oesophagoscopy and oesophagography (sensitivity and specificity of almost $100 \%$ when used together) was advocated in Zone I injuries owing to the dire consequences of missed injuries in this Zone. ${ }^{3}$ This led to a non-operative management rate of almost 66\%, but a high negative exploration rate of $19 \%$ in Zone II injuries. ${ }^{11}$ Hence, recent studies are advocating eliminating 'neck zone' differentiation during triage and management. $^{5}$ This so called No Zone approach says that comprehensive physical examination, combined with CTA, is adequate for triage to effectively identify or exclude vascular and aerodigestive injury after penetrating neck trauma. This approach is simple and has a low negative exploration rate, according to reports.

However, applying this approach in our case would have meant missing the occult hypopharyngeal injury that was not picked up by the CT scan. It may have been missed had it not

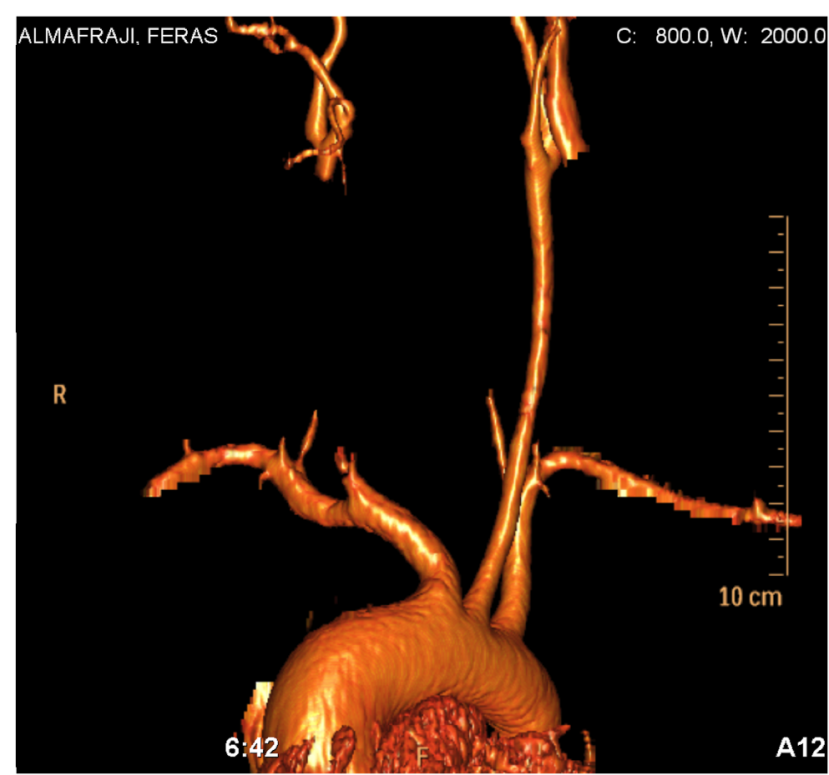

Figure 4 Arteriogram showing complete occlusion of right common carotid artery. 


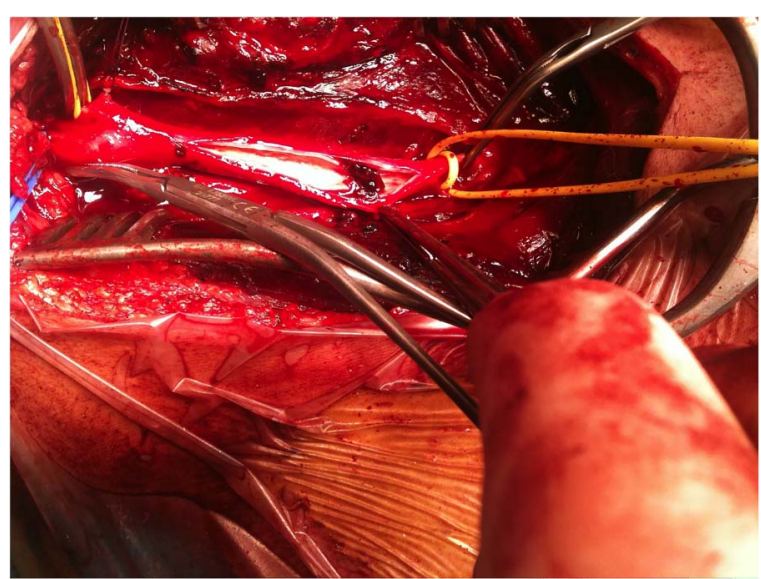

Figure 5 Intraoperative arteriotomy.

been for the surgical exploration carried out for the significant vascular injuries. A high index of suspicion and low threshold for intervention is necessary while managing Zone I injuries. Larger trials are thus necessary before implementing the No Zone approach, especially in patients with Zone I injuries.

The surgery for vascular injuries varies from simple debridement and direct anastomosis, to the use of venous and synthetic grafts for more extensive injuries. Shunts may be used in complex injuries. Carotid arteries are the most commonly involved vessels, the others being brachycephalic and vertebral, depending on zone of involvement. ${ }^{12}$ Repair of ICA and CCA is preferable to ligation when these are encountered during exploration of neck injuries. This is because revascularisation has a more favourable outcome ( $85 \%$ with favourable outcome) as compared to ligation $(50 \%)$ in patients with or without neurological deficit preoperatively.

Ligation of the carotid also carries a 50\% mortality rate and a $30 \%$ risk of stroke. In contrast, mortality rate after arterial repair is reported to be $17 \%$ in published studies. ${ }^{12}$ Ligation is advocated in comatose patients with lack of antegrade flow in the internal carotid and in cases where uncontrollable haemorrhage makes temporary shunt placement difficult. ${ }^{10}$ In patients with vascular injuries, hypovolemic shock or ICA injury, complete arterial transection and ligation rather than arterial repair are associated with poorer outcomes. ${ }^{12}$ The damaged CCA in this case was repaired using a LSV graft and the patient had an uneventful recovery.

Oesophageal perforations should be debrided, mobilised if necessary and repaired primarily. Adequate drainage is essential. A muscle flap may be used in large defects or when there is associated tracheal or vascular injury. ${ }^{13}$ This is because all repairs of the carotid artery in Zone I or Zone II are at risk for blowout in the postoperative period if there has been an associated injury to the cervical or upper thoracic oesophagus. ${ }^{14}$

\section{Learning points}

- Owing to the complex and heterogeneous nature of penetrating neck injuries (PNI), no single approach will be appropriate for all patients.

- Two definite principles in the management of PNI are: urgent operative intervention for unstable patients and a careful clinical work up of apparently stable patients, to determine the requirement for further investigations or interventions.

- The No Zone approach requires cautious clinical application.

- Patients with Zone I injuries may require a more aggressive approach.

Contributors MM was the operating surgeon for this study. NRB and MM participated in planning, writing and revising the study.

Competing interests None declared.

Patient consent Obtained.

Provenance and peer review Not commissioned; externally peer reviewed.

\section{REFERENCES}

1 Demetriades D, Skalkides J, Sofianos C, et al. Carotid artery injuries: experience with 124 cases. J Trauma 1989;29:91-4.

2 Roon AJ, Christensen N. Evaluation and treatment of penetrating cervical injuries. J Trauma 1979;19:391-7.

3 Stewart MG. Penetrating face and neck trauma. In: Byron J, Bailey JTJ, Shawn D, eds. Head \& neck surgery—otolaryngology. Vol 1. Newlands: Lippincott Williams and Wilkins, 2006:1017-25.

4 Inaba K, Munera F, McKenney $\mathrm{M}$, et al. Prospective evaluation of screening multislice helical computed tomographic angiography in the initial evaluation of penetrating neck injuries. J Trauma 2006;61:144-9.

5 Shiroff AM, Gale SC, Martin ND, et al. Penetrating neck trauma: a review of management strategies and discussion of the 'No Zone' approach. Am Surg 2013;79:23-9.

6 Mahmoodie M, Sanei B, Moazeni-Bistgani M, et al. Penetrating neck trauma: review of 192 cases. Arch Trauma Res 2012;1:14-18.

7 Kesser BW, Chance E, Kleiner D, et al. Contemporary management of penetrating neck trauma. Am Surg 2009;75:1-10.

8 Demetriades D, Theodorou D, Cornwell E, et al. Evaluation of penetrating injuries of the neck: prospective study of 223 patients. World J Surg 1997;21:41-7; discussion 7-8.

9 Nason RW, Assuras GN, Gray PR, et al. Penetrating neck injuries: analysis of experience from a Canadian trauma centre. Can J Surg 2001;44:122-6.

10 Burgess CA, Dale OT, Almeyda R, et al. An evidence based review of the assessment and management of penetrating neck trauma. Clin Otolaryngol 2012:37:44-52.

11 Prichayudh S, Choadrachata-Anun J, Sriussadaporn S, et al. Selective management of penetrating neck injuries using "no zone" approach. Injury 2015;46:1720-5.

12 du Toit DF, van Schalkwyk GD, Wadee SA, et al. Neurologic outcome after penetrating extracranial arterial trauma. J Vasc Surg 2003;38:257-62.

13 Moeng S, Boffard K. Penetrating neck injuries. Scand J Surg 2002;91:34-40.

14 Levine EA, Alverdy JC. Carotid-esophageal fistula following a penetrating neck injury: case report. J Trauma 1990;30:1588-90. 
Copyright 2015 BMJ Publishing Group. All rights reserved. For permission to reuse any of this content visit http://group.bmj.com/group/rights-licensing/permissions.

BMJ Case Report Fellows may re-use this article for personal use and teaching without any further permission.

Become a Fellow of BMJ Case Reports today and you can:

- Submit as many cases as you like

- Enjoy fast sympathetic peer review and rapid publication of accepted articles

- Access all the published articles

- Re-use any of the published material for personal use and teaching without further permission

For information on Institutional Fellowships contact consortiasales@bmjgroup.com

Visit casereports.bmj.com for more articles like this and to become a Fellow 